\title{
The level of student's pride in Ruteng (East Nusa Tenggara) high school on Bahasa
}

\author{
Ifran Nurtriputra, \\ Universitas Indraprasta PGRI \\ Heppy Atma Pratiwi *), \\ Universitas Indraprasta PGRI \\ *) Correspondences author: Jl. Nangka 58, Tanjung Barat, Jakarta Selatan 12530; Indonesia \\ e-mail: heppy.unindra@gmail.com
}

\begin{abstract}
The younger generation of Indonesia unconsciously affected and following every development of communication technology that many use a foreign language. The changes of language attitude of the students is inseparable from the literary situation in Indonesia. Indonesia society generally are bilingual and multilingual. In the literary situation like that there will be a language change in behavior that may not support the existence of one of the languages. From the perspective of sociolinguistics, the phenomenon of language attitude can determine the survival of the language. The object in this research is SMA 1 (1 High School) Ruteng, Nusa Tenggara Timur (NTT). The benefits of this research are able to be guidelines for the community's evocative, especially the young generation in addressing our national language with more pride, because the language is one of the nation's identity. The results of this research show that $57,58 \%$ feel proud to use the language of Indonesia, $42.42 \%$ regarded English is more attractive than in Bahasa. Students who support Bahasa became the international language of 29 respondents $(87,88 \%)$. The respondents have thought optimistic Bahasa can exist in an era of globalization only 23 of respondents $(69,70 \%)$ while 10 respondents $(30,30 \%)$ were still skeptical that Bahasa became the international language.
\end{abstract}

Key Words: Student, Pride, Language Attitude, Bahasa

Article History: Received: 15/10/2017; Revised: 23/11/2017; Accepted: 01/12/2017; Published: 20/12/2017

How to Cite (MLA $7^{\text {th }}$ ): Nurtriputra, Ifran and Heppy Atma Pratiwi. “The level of student's pride in Ruteng (East Nusa Tenggara) high school on Bahasa." Hortatori Jurnal Pendidikan Bahasa dan Sastra Indonesia 1.2 (2017): 187-196. Print/Online. Copyrights Holder: Nurtriputra, Ifran and Heppy Atma Pratiwi. First Publication: Hortatori Jurnal Pendidikan Bahasa dan Sastra Indonesia (2017).

\section{Pendahuluan}

Dalam berkomunikasi, manusia menggunakan bahasa. Di dalam penggunaan bahasa dibutuhkan juga imajinasi dan kemampuan untuk membayangkan, sebelum suatu informasi tersebut disampaikan kepada orang lain. Dengan menggunakan bahasa, dapat membantu pikiran kita lebih cepat. Perilakuperilaku yang berkaitan dengan komunikasi yang menggunakan bahasa ternyata dapat mempercepat perkembangan intelektual.

Bahasa Indonesia adalah lambang kebanggaan nasional. Bahasa Indonesia haruslah selalu dipelihara. diutamakan, dan dikembangkan sehingga mampu menjadi bahasa yang lebih bermartabat dan mampu menjadi salah salah bahasa internasional. Masyarakat penuturnya tidak boleh menyia-nyiakannya atau mengang $\neg$ gap remeh atau rendah. Untuk itu, usaha pembinaan bahasa selalu dilakukan secara terusmenerus, terencana, dan terarah.

Terkait dengan usaha pembinaan bahasa itu, ada fenomena kebahasaan yang perlu mendapat perhatian para pemangku kepentingan, pemerintah, dan masyarakat, yaitu feno $\neg$ mena sikap bahasa, terutama rasa bangga generasi muda, khususnya siswa SMA, terhadap bahasa Indonesia. Fenomena itu 
tidak terlepas dari perkembangan dan kemajuan dalam berbagai bidang kehidupan, khususnya kemajuan teknologi komunikasi yang begitu cepat. Generasi muda Indonesia secara tidak sadar terpengaruh dan mengikuti setiap perkembangan teknologi komunikasi yang banyak menggunakan bahasa asing. Mereka mungkin lebih membanggakan bahasa asing, terutama bahasa Inggris daripada bahasa Indonesia karena terkait langsung dengan kemajuan. Di samping itu, dengan menguasai bahasa asing itu, mereka beranggapan akan mudah mendapat pekerjaan atau kesuksesan dalam hidup dan mungkin menganggap dirinya lebih pintar atau lebih hebat daripada yang lain.

Perubahan sikap bahasa siswa tidak terlepas dari situasi kebahasaan di Indonesia. Masyarakat Indonesia pada umumnya bilingual (bahasa ibu dan bahasa Indonesia) atau multilingual (bahasa ibu, bahasa daerah lain, bahasa Indonesia, dan bahasa asing). Dalam situasi kebahasaan seperti itu akan terjadi perubahan perilaku berbahasa yang mungkin tidak mendukung keberadaan salah satu bahasa. Bahasa yang satu lebih dihargai daripada bahasa yang lain; bahasa yang satu dianggap lebih bergengsi daripada bahasa yang lain. Situasi demikian menyebabkan ketidakberuntungan suatu bahasa dan pada akhirnya bahasa itu punah.

Mengingat begitu cepatnya perubahan atau perkembangan yang terjadi dalam kehidupan ini, terutama perkembangan teknologi komunikasi, perlu dilakukan pengkajian terhadap ada atau tidaknya perubahan sikap atau perilaku masyarakat dalam berbagai bidang kehidupan, termasuk bidang bahasa. Salah satu sikap yang terkait dengan kehidupan berbahasa adalah rasa bangga terhadap bahasa yang dimiliki.

Dari uraian di atas dapat disimpulkan bahwa mengkaji bahasa tanpa mengaitkannya dengan masyarakat akan mengesampingkan beberapa aspek penting dan menarik, bahkan mungkin menyempitkan pandangan terhadap disiplin bahasa itu sendiri. Sosiolinguistik merupakan ilmu yang mempelajari bahasa dengan dimensi kemasyarakatan. Apabila kita mempelajari bahasa tanpa mengacu ke masyarakat yang menggunakannya sama dengan menyingkirkan kemungkinan ditemukannya penjelasan social bagi struktur yang digunakan. Dari perspektif sosiolinguistik, fenomena sikap bahasa (language attitude) dalam masyarakat multibahasa merupakan gejala yang menarik untuk dikaji, karena melalui sikap bahasa dapat menentukan keberlangsungan hidup suatu bahasa.

Objek dalam penelitian ini adalah SMA 1 Ruteng, Nusa Tenggara Timur (NTT). SMA 1 terletak di Jalan Harimau No. 1 Langke Rembong, Ruteng, Kabupaten Manggarai, Provinsi Nusa Tenggara Timur. SMA 1 Ruteng ini merupakan bahasa sehari-hari yang digunakan adalah bahasa daerah, yaitu bahasa Manggarai. Maka dari itu, kami tertarik meneliti tingkat kebanggaan mereka menggunakan bahasa Indonesia yang diakui mereka sebagai bahasa nasional.

\section{Metode}

Dalam penelitian sosiolinguistik untuk mendapatkan data yang akan diteliti, sering digunakan kuesioner, seperti yang dilakukan oleh Sugiyono (2010). Tulisan ini juga menggunakan kuesioner yang bersifat terbuka dan tertutup. Pertanyaan terbuka berkaitan dengan jawaban pertanyaaan yang diberikan yang tidak hanya terbatas pada ya atau tidak disediakan saja, tetapi juga disediakan opini dan pengetahuan responden.

SMA 1 Ruteng terdiri dari kelas X berjumlah 12 kelas, kelas XI berjumlah 10 kelas terbagi menjadi 3 kelas IPA, 5 kelas IPS, dan 2 kelas Bahasa, serta kelas XII yang berjumlah 11 kelas terbagi menjadi 3 kelas IPA, 6 kelas IPS, dan 2 kelas Bahasa dengan rata-rata 40 siswa tiap kelas. Adapun siswa yang dijadikan sampel memiliki peringkat sepuluh besar di kelas, yaitu berjumlah 330 siswa. Karena jumlahnya di atas 100, dapat diambil antara $10-15 \%$ atau $20-25 \%$ atau lebih, maka jumlah sampel yang akan diteliti $330 \times 10 \%=33$ siswa.

Dalam tulisan ini tingkat kebanggaan itu diukur secara kuantitatif dan kualitatif. Pengukuran secara kuantitatif hanya secara sederhana karena tidak menggunakan skala atau pengukuran seperti dalam penelitian Sugiyono (2010). Yang lebih diutamakan di sini adalah metode kualitatif deskriptif dengan mengkaji lebih jauh alasan jawaban yang diberikan responden.

Untuk mengetahui tingkat kebanggaan siswa SMA 1 Ruteng NTT terhadap bahasa Indonesia, diajukan pertanyaan dengan dua model pilihan jawaban: (1) jawaban pertanyaan ataupun pernyataan yang diberikan (model-1) dan (2) jawaban ya atau tidak disertai dengan opininya (model-2). Setelah menentukan pilihan, responden diminta memberikan alasan atas pilihan tersebut. 


\section{Hasil dan Diskusi}

\section{Sosiolinguistik}

Sosiolinguistik adalah ilmu antardisiplin antara sosiologi dan linguistik. Dua bidang ilmu yang mempunyai kaitan sangat erat. Sebagai objek dalam sosiolinguistik, bahasa tidak dilihat atau didekati sebagai bahasa, sebagaimana dilakukan oleh linguistik umum, melainkan dilihat atau didekati sebagai sarana interaksi atau komunikasi di dalam masyarakat manusia. Rumusan mengenai sosiolinguistik yang diberikan para pakar tidak akan terlepas dari persoalan hubungan bahasa dengan kegiatan-kegiatan atau aspek-aspek kemasyarakatan.

Ada dua istilah yang selama ini dianggap sama, yaitu sosiolinguistik dan sosiologi bahasa. Fishman (Chaer dan Agustina, 2004:5) mengatakan bahwa kajian sosiolinguistik lebih bersifat kualitatif, sedangkan kajian sosiologi bahasa bersifat kuantitatif. Jadi, sosiolinguistik lebih berhubugan dengan perincianperincian penggunaan bahasa yang sebenarnya, seperti deskripsi pola pemakaian bahasa dalam budaya tertentu, pilihan pemakaian bahasa atau dialek tertentu yang dilakukan penutur, topik, dan latar pembicaraan. Lain lagi dengan sosiologi bahasa yang lebih berhubungan dengan faktor-faktor sosial, yang saling bertimbal balik dengan bahasa atau dialek. Hal yang dibicarakan diantaranya perkembangan bilingualisme, perkembangan pembakuan bahasa, dan sebagainya.

Konferensi sosiolinguistik pertama yang dilangsungkan di University of California, Los Angeles, Amerika Serikat pada tahun 1974, telah merumuskan tujuh dimensi dalam penelitian sosiolinguistik. Ketujuh dimensi tersebut merupakan masalah dalam sosiolinguistik, yaitu

a. Identitas sosial dari penutur,

b. Identitas sosial dari pendengar yang terlibat dalam proses komunikasi,

c. Lingkungan sosial tempat peristiwa tutur terjadi,

d. Analisis sinkronik dan diakronik dari dialek-dialek sosial,

e. Penilaian sosial yang berbeda oleh penutur akan perilaku bentuk-bentuk ujaran,

f. Tingkatan variasi dan ragam linguistik, dan

g. Penerapan praktis dari penelitian sosiolingustik (Chaer dan Agustina, 2004: 5)

Berdasarkan dimensi tersebut, dapat dijadikan dasar dalam penelitian ini untuk mendalami penelitian pada sikap pengguna bahasa masyarakat Ruteng, Nusa Tenggara Timur pada umumnya dan SMA Ruteng, Nusa Tenggara Timur pada khususnya.

\section{Sikap Bahasa}

Kajian kebanggaan terhadap bahasa berkaitan dengan sikap, khususnya sikap bahasa. Banyak definisi yang berkaitan dengan sikap. Berkowitz (Azwar, 2011:4) menemukan lebih dari tiga puluh definisi sikap. Dalam Oxford Advanced Learner Dictionary didefinisikan bahwa sikap (attitude), berasal dari bahasa ltalia attitude, yaitu "Manner of placing or holding the body, dan Way of feeling, thinking, or behaving", 'Sikap adalah cara menempatkan atau membawakan diri atau cara merasakan, jalan pikirnn dan perilaku' (Ramdhani, 2008).

Terkait dengan definisi itu. Solomon (1999) dalam Sumarwan (2002:147) menyebutkan tricomponent model sebagai model sikap ABC (affective, behavioural, dan cognitive). Menurutnya, sikap terdiri atas tiga komponen, yaitu komponen afektif, komponen perilaku, dan komponen kognitif.

Sikap bahasa adalah posisi mental terhadap bahasa sendiri atau bahasa orang lain (Kridalaksana, 2001:197). Posisi mental itu dapat bersifat positif atau bersifat negatif sehingga muncul istilah sikap bahasa positif dan sikap bahasa negatif. Salah satu ciri sikap bahasa positif adalah kebanggaan hahasa (language pride) yang mendorong seseorang atau sekelompok orang untuk menjadikan bahasanya sebagai lambang identitas pribadi atau kelompoknya.

Esensi dari semuanya itu menyatakan bahwa sikap bahasa merupakan sikap yang dimiliki oleh para pemakai bahasa, baik yang dwibahasawan maupun yang multibahasawan terhadap suatu bahasa. Reaksi yang ditimbulkannya dapat berupa perasaan bangga, menge-jek, menolak, ataupun sekaligus menerima. Individu yang memiliki evaluasi negatif terhadap suatu bahasa akan berpendapat bahwa bahasa Indonesia tidak, mendukung kemajuan Indonesia. Sebaliknva, individu yang memiliki evaluasi positif akan berpendapat bahwa bahasa Indonesia dapat mencerdaskan kehidupan bangsa Indonesia. Indi $\neg$ vidu yang merespon negatif merasa malu atau ketinggalan zaman jika berbahasa Indonesia dan tidak mendukung eksistensi bahasa Indonesia. Sebaliknva, individu yang merespons positif merasa senang dan bangga terhadap bahasa Indonesia dan siap mempertahankan eksistensinya. 
Sikap orang terhadap bahasa mungkin saja seperti yang diperlihatkan dalam dua situasi yang berbeda, yaitu seperti berikut.

\begin{tabular}{lcc} 
& \multicolumn{2}{c}{ Situasi A } \\
& Pengertian & Sikap pada Bahasa \\
B1 & + & - \\
B2 & - & +
\end{tabular}

Dalam situasi A itu tergambar bahasa pertama dikuasai dengan baik atau dimengerti oleh penuturnva (+), tetapi bahasa ibu itu dianggap rendah atau mereka malu menggunakannya (-). Sebaliknya, bahasa kedua tidak dikuasai dengan baik oleh penutur bahasa pertama (-), tetapi bahasa tersebut mereka hargai lebih tinggi daripada bahasa mereka sendiri $(+)$ karena bahasa itu digunakan oleh orang yang terpandang, bahasa modern, dan membawa kemajuan atau dunia internasional. Sikap seperti itu mungkin saja terlihat dalam kehidupan berbahasa siswa.

\begin{tabular}{lcccc} 
& \multicolumn{2}{c}{ Situasi B } \\
$\mathrm{B} 1$ & + & Pengertian & & Sikap pada Bahasa \\
$\mathrm{B} 2$ & - & & +
\end{tabular}

Dalam situasi B itu tergambar bahasa pertama dikuasai dengan baik atau dimengerti oleh penuturnya (+) dan dihargai dengan baik atau dipandang sama dengan bahasa lainnya (+). Sebaliknya, bahasa kedua tidak dikuasai dengan baik oleh penutur bahasa pertama (-), tetapi bahasa tersebut mereka hargai sama dengan bahasa mereka sendiri (+). Sikap seperti itu mungkin saja juga terlihat dalam kehidupan berbahasa siswa.

Ada 35 pertanyaan ataupun pernyataan yang diajukan, baik pada angket tertutup maupun angket terbuka. Akan tetapi, hanya dua pertanyaan yang menjadi tolok ukur tingkat kebanggaan siswa SMA 1 Ruteng terhadap bahasa Indonesia (terdapat pada angket terbuka), yaitu (2) Apakah kamu bangga menggunakan bahasa Indonesia? dan (6) Apakah kamu mendukung bahasa Indonesia menjadi bahasa internasional, setidaknya di ASEAN?. Selain itu, ada dua pernyataan yang menunjukkan sikap siswa SMA 1 Ruteng terhadap kebanggaan pada bahasa Indonesia (terdapat pada angket tertutup), yaitu (1) Saya mengakui bahwa bahasa Indonesia lebih menarik daripada bahasa asing dan (9) Saya percaya bahasa Indonesia dapat eksis di era globalisasi.

Berdasarkan jawaban pertanyaan (2), diketahui bahwa tidak ada responden yang tidak bangga menggunakan bahasa Indonesia. Semua responden menjawab dengan ya (100\%). Jawaban pertanyaan itu memang akan menghasilkan jawaban seperti itu karena tidak mungkin siswa tidak bangga terhadap bahasa Indonesia. Namun, berdasarkan jawaban pernyataan (1), tingkat kebanggaan tersebut tidak didukung oleh sikap atau keyakinan semua responden untuk mengakui bahwa bahasa Indonesia lebih menarik daripada bahasa asing. Hal tersebut disebabkan ada empat belas responden $(42,42 \%)$, yang terdiri atas 8 responden perempuan dan 6 responden laki-laki.

Keempat belas responden tersebut, yaitu (1) R02L, (2) R03P, (3) R04P, (4) R06L, (5) R07P, (6) R09P, (7) R10P, (8) R12P, (9) R13P, (10) R14P, (11) R18L, (12) R19L, (13) R30L, dan (14) R31L. Jawaban keempat belas responden tersebut menggambarkan bahwa Siswa SMA 1 Ruteng tidak setuju bahwa bahasa Indonesia lebih menarik daripada bahasa asing. Dengan demikian, tingkat kebanggaan tersebut tidak didukung oleh sikap ataupun keinginan untuk mengutamakan penggunaan bahasa Indonesia dalam komunikasi sehari-hari.

Di samping itu, berdasarkan jawaban pertanyaan (6), diketahui bahwa 29 responden $(87,88 \%)$ mendukung bahasa Indonesia menjadi bahasa internasional, setidaknya di ASEAN, sedangkan hanya 4 responden $(12,12 \%)$ tidak mendukung bahasa Indonesia menjadi bahasa internasional. Responden yang tidak mendukung, yaitu (1) R05P, (2) R16P, (3) R18L, dan (4) R23P. Akan tetapi, dari 33 responden, 10 responden (30,30\%) bersikap skeptis terhadap bahasa Indonesia menjadi bahasa internasional, sedangkan 23 responden $(69,70 \%)$ berkeyakinan atau optimis bahasa Indonesia menjadi bahasa internasional di masa akan datang. Responden yang 
bersikap skeptis, yaitu (1) R01L, (2) R04P, (3) R05P, (4) R07P, (5) R10P, (6) R12P, (7) R14P, (8) R17L, (9) R22P, dan (10) R32L. Hal tersebut bertentangan dengan program Badan Bahasa dan pemerintah untuk mengupayakan bahasa Indonesia menjadi bahasa internasional.

\section{Alasan Bangga terhadap Bahasa Indonesia}

Ada beberapa alasan bangga terhadap bahasa Indonesia yang dikemukakan responden. Salah satu alasan itu dapat dilihat dalam jawaban responden berikut.

\begin{tabular}{|l|ll|}
\hline Resp. & \multicolumn{2}{|c|}{ Alasan } \\
\hline R01L & $\begin{array}{l}\text { Karena bahasa Indonesia adalah } \\
\text { bahasa yang satu. }\end{array}$ \\
\hline R10P & $\begin{array}{l}\text { Karena bahasa Indonesia adalah } \\
\text { bahasa persatuan. }\end{array}$ \\
\hline R23P & $\begin{array}{l}\text { Untuk melestarikan bahasa persatuan } \\
\text { kita. }\end{array}$ \\
\hline
\end{tabular}

Tiga responden itu mengemukakan alasan bangga menggunakan bahasa Indonesia karena bahasa Indonesia sebagai bahasa persatuan. Hal itu disebabkan bahasa Indonesia sebagai alat pemersatu berbagai kelompok etnik yang berbeda-beda latar belakang social budaya dan bahasanya. Dengan demikian, bahasa Indonesia digunakan pada situasi yang formal, sedangkan bahasa daerah digunaakan saat berkomunikasi dengan teman, rekan, keluarga, ataupun saudara dalam situasi nonformal. Bahasa daerah tetap dipergunakan untuk melestarikan bahasa daerah yang terdapat di Indonesia karena kondisi di Indonesia saat ini kurang lebih terdapat 746 bahasa daerah (Sugono, 2011:62). Selain itu, dengan pengutamaan penggunaan bahasa Indonesia menunjukkan jati diri bangsa Indonesia. Hal tersebut seperti alasan yang dikemukakan responden di bawah ini.

\begin{tabular}{|l|l|}
\hline Resp. & \multicolumn{1}{c|}{ Alasan } \\
\hline R07P & $\begin{array}{l}\text { Karena hal itu dapat mengenali saya } \\
\text { sebagai warga NKRI. }\end{array}$ \\
\hline R14P & $\begin{array}{l}\text { Karena bisa menumbuhkan identitas } \\
\text { saya sebagai WNI. }\end{array}$ \\
\hline R16P & $\begin{array}{l}\text { Karena bahasa Indonesia merupakan } \\
\text { bahasa yang merupakan identitas } \\
\text { seseorang. }\end{array}$ \\
\hline
\end{tabular}

Hal itulah yang membuat faktor pembeda antara bangsa Indonesia dan bangsa lain sebagai identitas bangsa. Walaupun tidak secara eksplisit dinyatakan sebagai identitas bangsa, jawaban responden berikut juga tergolong identitas bangsa. Dalam alasan itu tidak digunakan identitas secara eksplisit, tetapi bermakna identitas (bangsa).

\begin{tabular}{|l|l|}
\hline Resp. & \multicolumn{1}{c|}{ Alasan } \\
\hline R04P & $\begin{array}{l}\text { Karena Indonesia memiliki bahasa } \\
\text { sendiri, yaitu bahasa Indonesia tanpa } \\
\text { ada campuran dari bahasa asing }\end{array}$ \\
\hline R09P & $\begin{array}{l}\text { Karena saya harus menghargai } \\
\text { bahasa saya sendiri. }\end{array}$ \\
\hline R20L & karena bahasa negara saya \\
\hline
\end{tabular}

Alasan bangga terhadap bahasa Indonesia responden di atas dimulai dari diri sendiri (R04P), menghargai bahasa bangsa sendiri (R09P), dan bahasa negara saya (R20L). Ungkapan bangga dimulai dari 
menggunakan bahasa Indonesia yang menunjukkan sebagai orang Indonesia atau beridentitas Indonesia. Selanjutnya, bangga dimulai dari diri sendiri dalam hal itu tentu berimplikasi pada identitas yang dimiliki. Salah satunya ialah bahasa yang digunakan, yaitu bahasa Indonesia. Demikian pula alasan bahasa negara saya, mengimplikasikan sesuatu yang dimiliki atau identitas dari sebuah negara. Selain itu, paparan alasan di atas sesuai dengan kedudukan dan fungsi bahasa Indonesia, yaitu bahasa Indonesia sebagai bahasa nasional.

Selain alasan bahasa Indonesia sebagai bahasa persatuan seperti yang dipaparkan di atas, alasan yang lain ialah bahasa Indonesia sebagai bahasa negara yang sesuai dengan kedudukan dan fungsi bahasa Indonesia. Hal tersebut dapat dilihat dari alas an responden di bawah ini.

\begin{tabular}{|l|l|}
\hline Resp. & \multicolumn{1}{|c|}{ Alasan } \\
\hline R08P & $\begin{array}{l}\text { Karena merupakan bahasa resmi } \\
\text { negara }\end{array}$ \\
\hline
\end{tabular}

Hal itulah yang membedakan Indonesia dengan Singapura. Bahasa resmi Singapura ialah bahasa Inggris walaupun terdapat bahasa Melayu di Singapura. Adapun bahasa resmi Indonesia adalah bahasa Indonesia. Maksudnya ialah bahasa resmi tersebut bahasa yang digunakan pemerintah saat menjalankan pemerintahannya. Selain itu, walaupun tidak secara eksplisit dinyatakan sebagai bahasa negara, jawaban responden berikut juga tergolong bahasa negara. Dalam alasan itu tidak digunakan bahasa negara secara eksplisit, tetapi bermakna sebagai bahasa negara.

\begin{tabular}{|c|l|}
\hline Resp. & \multicolumn{1}{|c|}{ Alasan } \\
\hline R17L & $\begin{array}{l}\text { Karena itu (bangga menggunakan } \\
\text { bahasa Indonesia) sudah menjadi } \\
\text { kewajiban sebagai warga negara. }\end{array}$ \\
\hline R18L & $\begin{array}{l}\text { Karena dengan menggunakan bahasa } \\
\text { Indonesia, saya turut berpartisipasi } \\
\text { dalam bangsa. }\end{array}$ \\
\hline R33P & $\begin{array}{l}\text { Karena sebagai warga negara yang } \\
\text { baik, sudah semestinya kita } \\
\text { melestarikan bahasa kita agar bisa } \\
\text { menjadi bahasa Internasional. }\end{array}$ \\
\hline
\end{tabular}

Alasan bangga dimulai dari kesadaran sebagai Warga Negara Indonesia untuk wajib menggunakan bahasa dalam komunikasi sehari-hari (R17L). Kemudian, dengan menggunakan bahasa, berarti turut berpartisipasi dalam mengoptimalkan penggunaan bahasa, baik situasi formal maupun informal (R18L). Di samping itu, sudah semestinya kita melestarikan bahasa Indonesia di era globalisasi dan perdagangan bebas saat ini agar kita menjadi tuan rumah di negeri sendiri serta mengupayakan menjadikan bahasa Indonesia sebagai bahasa Internasional (R33P). Kedua hal tersebut tidak bisa berjalan dengan baik tanpa ada rasa bangga di dalam diri responden ataupun bangsa Indonesia.

Akan tetapi, tingkat kebanggan yang tinggi tersebut tidak dibarengi sikap atau keyakinan semua responden untuk mengakui bahwa bahasa Indonesia lebih menarik daripada bahasa asing. Berdasarkan 33 responden, 19 responden $(57,58 \%)$ menyatakan setuju bahwa bahasa Indonesia lebih menarik daripada bahasa asing. Hal tersebut menggambarkan bahwa responden benar-benar banggga terhadap bahasa Indonesia, yaitu dapat dilihat dari penggunaan bahasa Indonesia yang baik dan benar dalam komunikasi sehari-bari. Adapun 14 responden $(42,42 \%)$ menyatakan tidak setuju bahwa bahasa Indonesia lebih menarik daripada bahasa asing. Permasalahan tersebut dapat mengakibatkan terjadinya interferensi ataupun campur kode dalam proses berbahasa sehari-hari dan tidak menutup kemungkinan bahasa Indonesia akan ditinggalkan oleh penutur aslinya di masa yang akan datang. Dengan demikian, tingkat kebanggaan terhadap bahasa Indonesia harus direalisasikan dalam kehidupan sehari-hari, yaitu dengan mengoptimalkan penggunaan bahasa Indonesia yang baik dan benar. Selain itu, harus menanamkan pola pikir untuk cinta terhadap bahasa Indonesia dan mengubah pola pikir yang menyatakan bahwa bahasa asing, khususnya bahasa Inggris, lebih menjual daripada bahasa Indonesia. 


\section{Alasan yang Mendukung Bahasa Indonesia Menjadi Bahasa Internasional}

Berdasarkan data penelitian diketahui bahwa 29 responden $(87,88 \%)$ mendukung bahasa Indonesia menjadi bahasa internasional, setidaknya di ASEAN, sedangkan 4 responden $(12,12 \%)$ tidak mendukung bahasa Indonesia menjadi bahasa internasional. Responden yang mendukung bahasa Indonesia menjadi bahasa internasional mengindikasikan bahwa responden tersebut bangga terhadap bahasa Indonesia yang digunakan dalam komunikasi. Hal tersebut sejalan dengan alasan yang dikemukakan R06P. Selain bangga, juga dapat lebih mencintai bahasanya sendri (R32L), yang dikemukkakan di bawah ini.

\begin{tabular}{|l|l|}
\hline Resp. & \multicolumn{1}{c|}{ Alasan } \\
\hline R06P & $\begin{array}{l}\text { Karena jika bahasa Indonesia } \\
\text { menjadi bahasa Internasional, } \\
\text { bangsa Indonesia akan bangga }\end{array}$ \\
\hline R32L & $\begin{array}{l}\text { Agar Indonesia, khususnya warga } \\
\text { Indonesia merasa bangga dan lebih } \\
\text { mencintai bahasanya sendiri. }\end{array}$ \\
\hline
\end{tabular}

Adapun alasan responden mendukung bahasa Indonesia menjadi bahasa Internasional, yaitu sebagai berikut.

\begin{tabular}{|l|l|}
\hline Resp. & \multicolumn{1}{|c|}{ Alasan } \\
\hline R10P & $\begin{array}{l}\text { Karena bahasa Indonesia sudah } \\
\text { mencapai standar untuk bisa } \\
\text { dijadikan bahasa Internasional. }\end{array}$ \\
\hline R12P & $\begin{array}{l}\text { Karena dengan begitu bahasa } \\
\text { Indonesia dapat dipelajari banyak } \\
\text { negara dan dapat membantu } \\
\text { Indonesia dalam persaingan bidang } \\
\text { ekonomi, politik, sosial, dan } \\
\text { sebagainya. }\end{array}$ \\
\hline R24L & $\begin{array}{l}\text { Karena sebuah bahasa berhak ada di } \\
\text { tengah-tengah bahasa lain. }\end{array}$ \\
\hline
\end{tabular}

Pertama, bahasa Indonesia dapat menjadi bahasa Indonesia karena sudah memenuhi stadar (R10P), di antaranya dilihat dari jumlah penutur asli. Bahasa Indonesia saat ini menimpati peringkat 10 besar dalam hal jumlah penutur terbanyak di dunia.

Kedua, dengan begitu (bahasa Indonesia menjadi bahasa Internaisonal), bahasa Indonesia dapat dipelajari banyak negara dan dapat membantu Indonesia dalam persaingan bidang ekonomi, politik, sosaial, dan sebagainya (R12P). Saat ini bahasa Indonesia sudah dipelajari kurang lebih 200 penyelenggara Bahasa Indonesia untuk Penutur Asing (BIPA) di seluruh dunia (Sugono, 2013: 4). Bahasa Indonesia memiliki daya tarik tersendiri bagi warga negara asing tersebut. Bahkan linguis asing ada yang meneliti salah satu bahasa daerah Indonesia yang berada di daerah terkecil, terluar, dan tertinggal. Selain itu, bahasa Indonesia tidak hanya sebagai alat komunikasi antarbangsa (jika bahasa Indonesia menjadi bahasa Internasional) tetapi juga dapat meningkatkan perekonomian Indonesia. Apalagi akhir 2015, Masyarakat Ekonomi ASEAN akan berlaku di Indonesia. Hal tersebut membuat persaingan di bursa tenaga kerja akan semakin meningkat dan secara tidak langsung tenaga kerja yang ingin bekerja di Indonesia harus dapat menguasai dan menggunakan bahasa Indonesia.

Ketiga, karena sebuah bahasa berhak ada di tengah-tengah bahasa lain (R24L). Hal itu menandakan bahwa bahasa apapun termasuk bahasa Indonesia memiliki hak yang sama untuk dipelajari oleh siapapun dan digunakan dalam situasi apapun di sebuah negara tanpa melanggar aturan atau undang-undang setempat. Selain alasan tersebut di atas, alasan lain yang dikemukakan responden ialah sebagai berikut. 


\begin{tabular}{|c|c|}
\hline Resp. & $\begin{array}{c}\text { Alasan } \\
\end{array}$ \\
\hline R07P & $\begin{array}{l}\text { Karena bahasa } \text { Indonesia } \\
\text { merupakan bahasa yang mudah } \\
\text { atau cepat dipahami dan } \\
\text { dihafalkan. }\end{array}$ \\
\hline R14P & $\begin{array}{l}\text { Karena menurut saya bahasa } \\
\text { Indonesia adalah bahasa yang } \\
\text { lebih mudah } \\
\text { dibandingkan dengan bahasa } \\
\text { negara lain. }\end{array}$ \\
\hline $\mathrm{R} 25 \mathrm{~L}$ & $\begin{array}{l}\text { Karena menurut saya, bahasa } \\
\text { Indonesia itu gampang utnuk } \\
\text { dipahami penulisan dan cara } \\
\text { membaca serta mengucapan tidak } \\
\text { ada yang berbeda. }\end{array}$ \\
\hline
\end{tabular}

Tiga responden itu mengemukakan alasan mendukung bahasa Indonesia menjadi bahasa internasional karena bahasa Indonesia mudah dipelajari siapapun karena tidak mengenal strata dan tata bahasanya sederhana, tidak seperti bahasa yang lain dan bahasa Indonesia satu rumpun dengan bahasa melayu yang merupakan bahasa resmi di negara ASEAN.

Meskipun demikian, beberapa responden kurang mendukung bahasa Indonesia menjadi bahasa internasional karena terkait dengan pola pikir negatif terhadap bahasa Indonesia (R16P) dan (R18L) serta sebagai identitas daerah asli penutur tersebut (R23P).

\begin{tabular}{|l|l|}
\hline Resp. & \multicolumn{1}{|c|}{ Alasan } \\
\hline R16P & $\begin{array}{l}\text { Karena bahasa Internasional } \\
\text { adalah bahasa Inggris. }\end{array}$ \\
\hline & $\begin{array}{l}\text { Karena bahasa Indonesia tidak } \\
\text { terlalu memberikan pengaruh } \\
\text { kepada negara lain dalam dunia } \\
\text { internasional. }\end{array}$ \\
\hline R18L & $\begin{array}{l}\text { Karena bahasa Indonesia dapat } \\
\text { menjadi identitas daerah asli orang } \\
\text { tersebut. }\end{array}$ \\
R23P
\end{tabular}

Dukungan bahasa Indonesia menjadi bahasa internasional yang sejumlah 29 responden $(87,88 \%)$, tidak dibarengi sikap atau keyakinan bahwa bahasa Indonesia akan eksistensi di era globalisasi. Hal itu disebabkan sepuluh responden (30,30\%) memiliki pemikiran skeptis terhadap bahasa Indonesia bisa eksis di era globalisasi. Di samping itu, sikap tersebut secara tidak langsung menunjukkan bahwa tidak semua responden bangga terhadap bahasa Indonesia walaupun 33 responden (100\%) menyatakan bangga terhadap bahasa Indonesia seperti yang sudah dipaparkan di atas. Jika responden bangga terhadap bahasa Indonesia, seharusnya responden tersebut memiliki pemikiran dan sikap yang optimis terhadap eksistensi bahasa Indonesia di era globalisasi.Sementara itu, responden yang optimis terhadap bahasa Indonesia bisa eksis di era globalisasi 23 responden $(69,70 \%)$. Dua puluh tiga responden itulah yang benar-benar bangga terhadap bahasa Indonesia. Jika bangga terhadap bahasa Indonesia, dalam situasi apapun tetap harus menggunakan bahasa Indonesia dengan baik dan benar, bersikap optimis terhadap masa depan bahasa Indonesia, menjaga dan melestarikan bahasa Indonesia dari segala ancaman (budaya ataupun bahasa) dari luar agar menjadi tuan rumah di negeri sendiri serta mengupayakan bahasa Indonesia menjadi bahasa internasional. 


\section{Simpulan}

Kebanggan siswa SMA 1 Ruteng terhadap bahasa Indonesia dapat dikatakan masih tinggi. Jawaban pertanyaan (2) pada angket terbuka membuktikan bahwa semua responden (100\%) bangga terhadap bahasa Indonesia. Akan tetapi, ketika dihadapkan pada pilihan bahasa yang diberikan pernyataan (1) model-1, ternyata ada pergeseran kebanggaan. Responden yang bangga terhadap bahasa Indonesia tidak lagi 100\%, tetapi menjadi 57,58\%. Hal tersebut membuktikan bahasa asing, khususnya bahasa Inggris oleh 42,42\% lebih menarik daripada bahasa Indonesia. Alasan yang banyak dikemukakan oleh siswa yang bangga terhadap bahasa Indonesia adalah bahasa Indonesia merupakan bahasa pemersatu bangsa dan identitas/jati diri bangsa. Selain itu, alasan lainnya ialah bahasa Indonesia sebagai bahasa resmi negara.

Ketika dihadapkan pada pertanyaan (6) model-2 dan pernyataan (9) model-1, jawaban siswa merisaukan, khususnya yang berkaitan dengan jawaban pernyataan (9) model-1. Siswa yang mendukung bahasa Indonesia menjadi bahasa internasional berjumlah 29 responden $(87,88 \%)$. Akan tetapi, responden yang memiliki pemikiran optimis ihwal bahasa Indonesia dapat eksis di era globalisasi hanya 23 responden $(69,70 \%)$, sedangkan 10 responden $(30,30 \%)$ masih beripikiran skeptis terhadap bahasa Indonesia menjadi bahasa internasional. Adapun alasan utama mendukung bahasa Indonesia menjadi bahasa internasional adalah karena responden bangga terhadap bahasa Indonesia yang digunakan saat berkomunikasi. Alasan yang lain ialah karena bahasa Indonesia berpotensi menjadi bahhasa internasional dilihat dari jumlah penuturnya salah satu yang terbanyak di dunia dan bahasa Indonesia mudah untuk dipelajari serta memiliki daya tarik tersendiri sehingga saat ini sudah dipelajari kurang lebih 200 penyelenggara BIPA di penjuru dunia. Di samping itu, dengan mendukung bahasa Indonesia menjadi bahasa internasional, perekonomian Indonesia akan berkembang dan meningkat. Berdasarkan dua pertanyaan di atas itu, terlihat bahwa kebanggga terhadap bahasa Indonesia sekali lagi akan menurun ketika dioposisikan dengan bahasa asing dan tidak diikuti oleh sikap atau pemikiran yang positif terhadap bahasa Indonesia.

Pada masa yang akan datang ada kemungkinan kebanggaan terhadap bahasa Indonesia akan menurun, seperti situasi A yang dikemukakan Grimes hasil tulisan ini membuktikan bahwa ketika dihadapkan dengan pilihan bahasa dan pengutamaan bahasa Indonesia, ternyata ada responden yang tidak mendukung.

Berdasarkan hasil penelitian di atas, menunjukkan bahwa siswa perlu ditanamkan pola pikir dan sikap yang positif dan optimis ihwal bahasa Indonesia. Hal itu dilakukan agar siswa bangga terhadap bahasa Indonesia. Di samping itu, penelitian ini hanya sebatas mengkaji kuantitas dan kualitas kebanggaan siswa SMA 1 Ruteng. Hasilnya perlu didukung oleh penelitian sejenis pada daerah (provinsi atau kota atau kabupaten) lain sehingga diperoleh gambaran atau simpulan yang menyakinkan untuk kepentingan pembinaan bahasa ke depan. Selain itu, penelitian ini belum mengkaji lebih jauh bagaimana perbedaan kebanggaan siswa berdasarkan variabel tertentu, misalnya siswa SMA negeri dengan SMA swasta.

\section{Ucapan Terima Kasih}

Berbagai hambatan yang dilalui tidak ada artinya tanpa semangat dan dukungan dari beberapa pihak. Puji syukur pada Allah Sang Maha yang telah memberikan kami kesempatan dan kesehatan untuk dapat menjalankan semua proses penelitian sampai selesai. Keluarga kami tercinta adalah support system terbesar, karena dengan ikhlas mengizinkan kami pergi jauh untuk melakukan penelitian ini. Tak kalah pentingnya peneliti mengucapkan terima kasih dengan hormat kepada Kepala, Guru, dan Siswa-Siswi SMA 1 Ruteng Nusa Tenggara Timur selaku subjek penelitian, yang telah meluangkan waktu untuk membantu proses pengisian data dan wawancara yang kami butuhkan. Terakhir, seluruh pihak yang telah membantu proses penelitian ini yang tidak dapat kami sebutkan satu per satu.

\section{Daftar Rujukan}

Azwar, Saifudin. Sikap Manusia: Teori dan Pengukurannya. Edisi 2Yogyakarta: Pustaka Pelajar, 2011. Chaer, Abdul dan Leonie Agustina. Sosiolinguistik Perkenalan Awal. Jakarta: Rineka Cipta, 2004.

Kridalaksana. Harimurti. Kamus Linguistik. Jakarta: PT Gramedia Pustaka Utama, 2001.

Ramdhani, Niela. Pembentukan dan Perubahan Sikap. http:/neila.staff.ugm.ac.id/wordpress/wpcontent/uploads/2009/09/bab2a1- attitude.pdf diunggah , 2008. 
196 The level of student's pride in Ruteng (East Nusa Tenggara)

high school on Bahasa

Sumarwan, Ujang. Perilaku Konsumen: Teori dan Penerapannya dalam Pemasaran. Jakarta: Ghalia Indonesia, 2002.

Sugiyono dan S.S.T. Wisnu Sasangka. Sikap Bahasa Masyarakat Kota Besar Indonesia terhadap Bahasa Indonesia, Bahasa Daerah, dari Bahasa Asing. Dalam Metalingua. Vol. 8, No. 2.hlm 178-189, 2010. (online)

Sugono, Dendy. Perencanaan Bahasa Daerah di Indonesia. Dalam

Salingka: Majalah Sastra dan Bahasa: 62-73, 2011.

Sugono, Dendy. Strategi Pengembangan BIPA. dalam Konferensi Asosiasi Pengajaran BIPA, Salatiga, 2003. 